\title{
Metagenome analyses of corroded concrete wastewater pipe biofilms reveal a complex microbial system
}

\author{
Vicente Gomez-Alvarez, Randy P Revetta and Jorge W Santo Domingo*
}

\begin{abstract}
Background: Concrete corrosion of wastewater collection systems is a significant cause of deterioration and premature collapse. Failure to adequately address the deteriorating infrastructure networks threatens our environment, public health, and safety. Analysis of whole-metagenome pyrosequencing data and 16S rRNA gene clone libraries was used to determine microbial composition and functional genes associated with biomass harvested from crown (top) and invert (bottom) sections of a corroded wastewater pipe.

Results: Taxonomic and functional analysis demonstrated that approximately $90 \%$ of the total diversity was associated with the phyla Actinobacteria, Bacteroidetes, Firmicutes and Proteobacteria. The top (TP) and bottom pipe (BP) communities were different in composition, with some of the differences attributed to the abundance of sulfide-oxidizing and sulfate-reducing bacteria. Additionally, human fecal bacteria were more abundant in the BP communities. Among the functional categories, proteins involved in sulfur and nitrogen metabolism showed the most significant differences between biofilms. There was also an enrichment of genes associated with heavy metal resistance, virulence (protein secretion systems) and stress response in the TP biofilm, while a higher number of genes related to motility and chemotaxis were identified in the BP biofilm. Both biofilms contain a high number of genes associated with resistance to antibiotics and toxic compounds subsystems.

Conclusions: The function potential of wastewater biofilms was highly diverse with level of COG diversity similar to that described for soil. On the basis of the metagenomic data, some factors that may contribute to niche differentiation were $\mathrm{pH}$, aerobic conditions and availability of substrate, such as nitrogen and sulfur. The results from this study will help us better understand the genetic network and functional capability of microbial members of wastewater concrete biofilms.
\end{abstract}

\section{Background}

Concrete corrosion of wastewater collection systems is a significant cause of deterioration and premature failure. In the U.S., costs associated with maintaining an estimated 800,000 miles of wastewater collection infrastructure are approximately $\$ 4.5$ billion per year [1]. Many systems may be beyond their design life and must be replaced because they cannot be rehabilitated [2]. Failure to adequately address the deteriorating infrastructure networks threatens our environment, public health, and safety. In wastewater collection systems microbial-induced

\footnotetext{
* Correspondence: Santodomingo.Jorge@epa.gov

U.S. Environmental Protection Agency, Office of Research and Development, Cincinnati, OH, 45268, USA
}

\section{Biomed Central}

(c) 2012 Gomez-Alvarez et al.; licensee BioMed Central Ltd. This is an Open Access article distributed under the terms of the Creative Commons Attribution License (http://creativecommons.org/licenses/by/2.0), which permits unrestricted use, distribution, and reproduction in any medium, provided the original work is properly cited. concrete corrosion (MICC) may occur in areas under higher concentrations of hydrogen sulfide $\left(\mathrm{H}_{2} \mathrm{~S}\right)$ [3-5]. The primary source of sulfur is sulfate $\left(\mathrm{SO}_{4}^{2-}\right)$ which can be reduced by sulfate-reducing bacteria (SRB) to hydrogen sulfide $\left(\mathrm{H}_{2} \mathrm{~S}\right)$ under anaerobic conditions. $\mathrm{H}_{2} \mathrm{~S}$ is transferred across the air-water interface to the sewer atmosphere where chemoautotrophic bacteria on the pipe surface, including sulfide-oxidizing bacteria ( $\mathrm{SOB}$ ), convert the $\mathrm{H}_{2} \mathrm{~S}$ to biogenic sulfuric acid $\left(\mathrm{H}_{2} \mathrm{SO}_{4}\right)$. Biogenic sulfuric acid $\left(\mathrm{H}_{2} \mathrm{SO}_{4}\right)$ can be generated by various microbial species [6-9].

While many of the microorganisms and general mechanism involved in MICC has been known for decades, and recent studies using molecular-based approaches have more accurately described the microbial ecology of 
these engineered systems $[6,8,9]$, a better understanding of the metabolic processes and functional capabilities is needed to develop new approaches to mitigate MICC and its associated effects. The objective of this study was to characterize the microbial community of concrete wastewater biofilms and their functional capability based on molecular analyses of metagenome libraries and to compare it with 16S rRNA gene sequences from previously generated clone libraries [7-11]. Specifically, we sampled biofilms from two sections of a severely corroded concrete wastewater pipe to obtain a better understanding of microbial community colonization processes and mechanisms of concrete deterioration. To our knowledge this is the first published report utilizing metagenomics to elucidate microbial community functional capabilities involved in MICC in wastewater collection systems.

\section{Methods}

\section{Sampling and extraction of total DNA from biofilms}

Biofilm samples were collected from two sections of a corroded concrete sewer pipe located in the Cincinnati metropolitan area. The excavated pipe was installed in 1949 and exposed to residential waste. Biomass was removed from the crown (top section of the pipe, TP) and invert (bottom, BP) sections using a sterile metal spatula by scraping approximately $4 \mathrm{~cm}^{2}$ surface area of each material. Biomass was then transferred to sterile tubes and stored at $-20^{\circ} \mathrm{C}$. Total DNA was extracted using UltraClean Soil DNA kit following the manufacturer's instructions (MoBio Laboratories Inc., Solana Beach, CA) and used as a template for the generation of pyrosequencing metagenome libraries.

\section{S rRNA gene sequence analyses}

Sequences from Bacteroidetes $(n=236)$, sulfate reducing $(n=56)$ and sulfur oxidizing $(n=164)$ bacteria obtained from a previous study [11] were used to develop phylogenetic trees. Briefly, $16 \mathrm{~S}$ rRNA gene primers $8 \mathrm{~F}$ and $787 \mathrm{R}$ were used to generate community PCR products, which were then cloned using TOPO TA vectors. Clones were sequenced in both directions and assembled using Sequencher software (Gene Codes Corp, Ann Arbor, $\mathrm{MI}$ ). Sequences were assigned to specific bacterial groups using MOTHUR v1.19.2 (http://www.mothur. org) with $97 \%$ sequence identity as the cut off point for each Operational Taxonomic Unit (OTU). Phylogenetic trees were constructed from the alignments based on the Maximum Likelihood method and calculated using Tamura-Nei model [12]. MEGA v5.03 [13] was used to build trees using 100 replicates to develop bootstrap confidence values. The Classifier tool of the Ribosomal Database Project II release 10.26 [14] and BLASTn [15] were used to classify and identify the nearest neighbors.

\section{Cluster analysis of wastewater concrete biofilms}

Cluster analysis based on the transformed $(\log [\mathrm{x}+1])$ relative abundance data was used to compare communities associated with different wastewater concrete biofilms. First, we estimated the taxonomic distribution at the genus level of each microbial community from $16 \mathrm{~S}$ rRNA gene pyrosequences generated in this study and Sanger-chemistry $16 \mathrm{~S}$ rRNA gene sequences generated in previous studies [7-10]. This information was used to generate Bray-Curtis similarity coefficients of the transformed data using the software PAST v2.03 [16]. This estimator compares the structures by accounting for the abundance distributions of attributes (e.g. species). Dendrograms indicating relationship of biofilms generated by comparing similarity coefficients estimates among sample sites were calculated using the UPGMA method with the software MEGA v5.03 [13].

\section{Metagenomic studies}

Pyrosequencing was performed using the 454 Life Sciences GS-FLX Titanium ${ }^{\circledR}$ platform. Prior to sequence analysis we implemented a dereplication pipeline (http:// microbiomes.msu.edu/replicates) to identify and remove clusters of artificially replicated sequences, i.e. reads that began at the same position but varied in length or contained a sequencing discrepancy [17]. Filter parameters included a cutoff value of 0.9 , no length difference requirement and an initial base pair match of 3 base pairs. Metagenome sequence data (i.e. singleton reads) were processed using two fully automated open source systems: (1) the MG-RAST v3.0 pipeline (http://metagenomics.anl. gov) [18] and (2) the Rapid Analysis of Multiple Metagenomes with a Clustering and Annotation Pipeline (RAMMCAP) [19], available from the Community Cyberinfrastructure for Advanced Microbial Ecology Research and Analysis (CAMERA, http://camera.calit2.net). The analysis included phylogenetic comparisons and functional annotations. All analyses were performed with an expected e-value cutoff of $1 \mathrm{e}^{-05}$ without preprocessing filtering. The metagenomes generated in this paper are freely available from the SEED platform (Projects: 4470638.3 and 4470639.3). Taxonomic relationships between metagenomes were analyzed by two complementary analyses using the MG-RAST pipeline. First, $16 \mathrm{~S}$ rRNA gene sequences were retrieved and compared to a database of known 16S rRNA gene sequences (e.g. SSU SILVA rRNA database project). Each read that matched a known sequence was assigned to that organism. In the second analysis putative open reading frames (ORF) were identified and their corresponding protein sequences were searched with BLAST against the M5NR database [18]. The M5NR is an integration of many sequence databases into one single, searchable database. This approach provided us with information for assignments to taxonomic 
units (e.g. class, families and species) with the caveat a protein sequence could be assigned to more than one closely related organism. Taxonomic assignments were resolved using the lowest common ancestor (LCA) approach [18].

\section{Functional analysis and reconstruction of metabolic pathways}

ORFs were identified and their corresponding protein sequences were annotated (i.e. assigned functions) by comparison to SEED, Pfam, TIGRfam and COG databases $[18,19]$. Identified proteins were assigned with their respective enzyme commission number (EC). Prior to quantitative characterization, counts were normalized (relative abundance) against the total number of hits in their respective database (e.g. SEED, COG, etc.) using effective sequence counts, a composite measure of sequence number and average genome size (AGS) of the metagenome as described by Beszteri et al. [20]. Raes and colleagues [21] defined the AGS as an ecological measure of genome size that also includes multiple plasmid copies, inserted sequences, and associated phages and viruses. Previous studies $[20,21]$ demonstrated that the relative abundance of genes will show differences if the AGS of the community fluctuate across samples. The Chaol and ACE estimators of COG richness were computed with the software SPADE v2.1 (http://chao. stat.nthu.edu.tw) [22] using the number of individual COGs per unique COG function. The proportion of specific genes in metagenomes also provides a method for comparison between samples. By dividing the AGS to the amount of DNA (in kb) per function-specific gene, one can determine the proportion of genomes in the metagenome that are capable of that function [23]. However, direct comparison of the distribution of different functions (i.e. gene) was not established between the metagenome, since length and copy number of the gene was not incorporated in the formula. To define whether a gene was enriched in the environment we calculated the odds ratio or the relative risk of observing a given group in the sample relative to the comparison dataset [24]. The odds ratios were calculated as follows: (A/B)/ $(C / D)$ where $A$ is the number of hits to a given category in the $x$ dataset (e.g. TP metagenome), $\mathrm{B}$ is the number of hits to all other categories in the $x$ metagenome, $\mathrm{C}$ is the number of hits to a given category in the $y$ dataset (e.g. BP metagenome), and D is the number of hits to all other categories in the $y$ dataset. We then used the metagenome profiles to calculate the statistical differences between the two samples based on the Fisher's exact test with corrected $q$-values (Storey's FDR multiple test correction approach) using the software package STAMP v1.07 [25]. Such randomization procedures were used to find statistically distinct functional groups in each of the wastewater pipe biofilms. Genes with an odds ratio $>1$ and $q<0.05$ were defined as enriched and genes with an odds ratio $<1$ and $q<0.05$ as under-represented.

\section{Taxonomic assignments of metabolic genes}

Sequences assigned to the sulfur and nitrogen pathways were identified and retrieved from MG-RAST and RAMMCAP output files (see Metagenomic studies section). Selected genes were taxonomically classified by BLASTX analyses against the NCBI non-redundant protein sequence (nr) database using the CAMERA 2.0 server [26]. Assignment and comparison of taxonomic groups and tree representation of the NCBI taxonomy were performed using the software MEGAN v4.67.1 [27]. The metagenomes were compared at the genus level (when available) using absolute reads counts with default parameters for the lowest common ancestor (LCA) algorithm of min-score of 35, a top-percent value of $10 \%$ and min-support of 5 .

\section{Results and discussion}

Metagenome library construction

In this study, we analyzed the microbial communities of biofilms established on the top (TP) and bottom (BP) of a corroded wastewater concrete pipe. The excavated pipe sections were installed 60 years prior to this study and were replaced due to integrity failure resulting from corrosion (i.e. the crown losing a significant portion of original width). A total of 1,004,530 and 976,729 reads averaging 370 and 427 base pairs for the TP and BP metagenomes, respectively, were analyzed in this study (Table 1). We identified and removed artificially replicated reads, which represented a total of $14 \%$ and $12 \%$ of sequences from the TP and BP metagenomes, respectively. Less than $50 \%$ of our reads were annotated as specific genes or functional group by either CAMERA v2 or MG-RAST v3 (Table 1). The relatively low number of annotated genes is common in metagenomic studies [28-30] and is primarily due to the relatively small and biased diversity of genomes sequenced, novel genes yet to be placed in functional groups, and sequencing and processing errors. For diverse and not well-understood systems such as wastewater biofilms, annotation of gene functions can also be limited by the extent of the database of previously sequenced and characterized genes [31]. Nonetheless, high-quality reads with a comparable average genome size were generated in this study, which allowed us to compare the metagenomic data, in terms of what proportion of genomes harbor a particular function [23].

\section{Wastewater biofilms}

The taxonomic classification of 629,161 (TP) and 641,853 (BP) sequence reads was assigned using the 
Table 1 Characterization of $\mathbf{4 5 4}$ pyrosequenced libraries from the microbial community of biofilms

\begin{tabular}{lll}
\hline & $\begin{array}{l}\text { Top pipe } \\
\text { (TP) }\end{array}$ & $\begin{array}{l}\text { Bottom } \\
\text { pipe (BP) }\end{array}$ \\
\hline reads & 1004530 & 976729 \\
avg reads (bp) & 370 & 427 \\
dataset size $\left(10^{8} \mathrm{bp}\right)$ & 3.2 & 3.7 \\
reads for analysis & 862893 & 856080
\end{tabular}

\section{CAMERA v2}

COG hits $^{\dagger}$

$$
370393
$$$$
389807
$$

Pfam hits ${ }^{\dagger}$

338966

352466

TIGRfam hits ${ }^{\dagger}$

579127

607388

MG-RAST v3

reads matching to a taxa ${ }^{\dagger}$

reads matching to a subsystems ${ }^{\dagger}$

no. of subsystems (function level)

$\begin{array}{ll}629161 & 641853 \\ 425346 & 427295 \\ 5633 & 6117\end{array}$

Annotated proteins (\%) [SEED]

$\begin{array}{lll}\text { Bacteria } & 95.5 & 94.1 \\ \text { Archaea } & 0.5 & 1.3 \\ \text { Virus } & 0.1 & 0.1 \\ \text { Eukaryota } & 0.6 & 0.3 \\ \text { Unclassified } & 3.3 & 4.2 \\ \text { Comparative metagenome } & & \\ \text { average genome size [Mb] } & 3.3 & 3.3 \\ \text { ESC of COG hits } & 369671 & 390570\end{array}$

SPrior to sequence analysis we implemented a dereplication pipeline to identify and remove clusters of artificially replicated sequences [17].

${ }^{\dagger} \mathrm{E}$-value cut-off $>1 \mathrm{e}^{-05}$.

*Average genome size and effective sequence count (ESC) as calculated by Beszteri et al. [20].

SEED database (MG-RAST v3). Based on our results, Bacteria-like sequences dominated both samples $(>94 \%$ of annotated proteins) (Table 1). Approximately $90 \%$ of the total Bacteria diversity was represented by the phyla Actinobacteria, Bacteroidetes, Firmicutes and Proteobacteria (Figure 1). The bacterial community was diverse with representatives of more than 40 classes. Taxonomic annotation of the functional genes profiles (i.e. annotated proteins) displayed a similar pattern of diversity to taxonomic analysis based on 16S rRNA genes identified from the metagenome libraries (Additional file 1, Figure S2).

Some annotated proteins were associated with archaeal genes, and to a lesser extent to viral and eukaryotic genes (Table 1, Figure 1). Specifically, a total of 2,837 (TP) and 8,237 (BP) Archaea-related functions were identified using the SEED database. The majority of the annotated sequences in both samples were related to proteins affiliated with archaea members of the class Methanomicrobia. Although, phages are extremely abundant and diverse in natural systems, we were able to identify only a low number of sequences (696), perhaps due to the loss of viruses during the sample concentration or DNA extraction steps [32]. Nonetheless, the results indicated that the community composition and structure of viruses parallels the distribution of Bacterial representatives [33]. Specifically, phages associated to the classes Actinobacteria, Alphaproteobacteria, Betaproteobacteria, Gammaproteobacteria and Deltaproteobacteria were found to be the dominant phage sequences in our metagenomes (Figure 1). Phages can potentially be used as biocontrol agents to specifically control some of the bacteria implicated in corrosion. Future studies should focus on the use of viral concentration methods to further study the occurrence of phage sequences that could be use as targets to monitor biocorrosion bacteria in wastewater concrete pipes.

\section{Comparative microbial community analysis}

In previous studies, biofilms were analyzed from the surface of primary settling tanks from a domestic wastewater treatment plant $[7,8]$ and from coupons placed in a collection system manhole [9], while our study focused on biofilms from top and bottom of a corroded pipe. In spite of the differences in sample matrix, some trends in the bacterial distribution between concrete wastewater biofilms were observed (Additional file 1, Figure S3). For example, the bottom of the pipe (BP) is characterized by direct contact and long residence time with wastewater, which maintains an ideal anaerobic environment for SRB. In fact, obligate anaerobes of the class Deltaproteobacteria (16\%) were the dominant cluster in BP biofilm (Figure 1). The BP harbored anaerobic bacteria normally found in the human gut such as members of the Bacteroidia (11\%) and Clostridia (5.1\%) classes (Figure 1 and Additional file 1, Figure S2). This was also supported by data from $16 \mathrm{~S}$ rRNA gene clone libraries (Additional file 1, Figure S4). We also retrieved sequences from the gut-related archaeal species Methanobrevibacter smithii in the BP metagenome [34]. These findings are not surprising, as human fecal bacteria has also been noted in concrete biofilms in previous studies [7-9].

Sections of wastewater pipes exhibit conditions that are favorable for the establishment of oxic zones, e.g., at the top of the pipe (TP). In fact, the dominant TP biofilm members were associated with aerobic and facultative anaerobic bacteria (e.g. Thiobacillus, Acidiphilium, Xanthomonas, Bradyrhizobium). The biofilms did not contain a significant presence of photosynthetic organisms (e.g. Cyanobacteria), which dominated biofilms in concrete corroded city-surface structures [10]. The latter is supported by the low number of genes assigned to the photosynthesis subsystems in our metagenome libraries (Additional file 1, Figure S1).

Taxonomic analysis based on annotated proteins show two distinct archaeal communities (Figure 1). The BP 


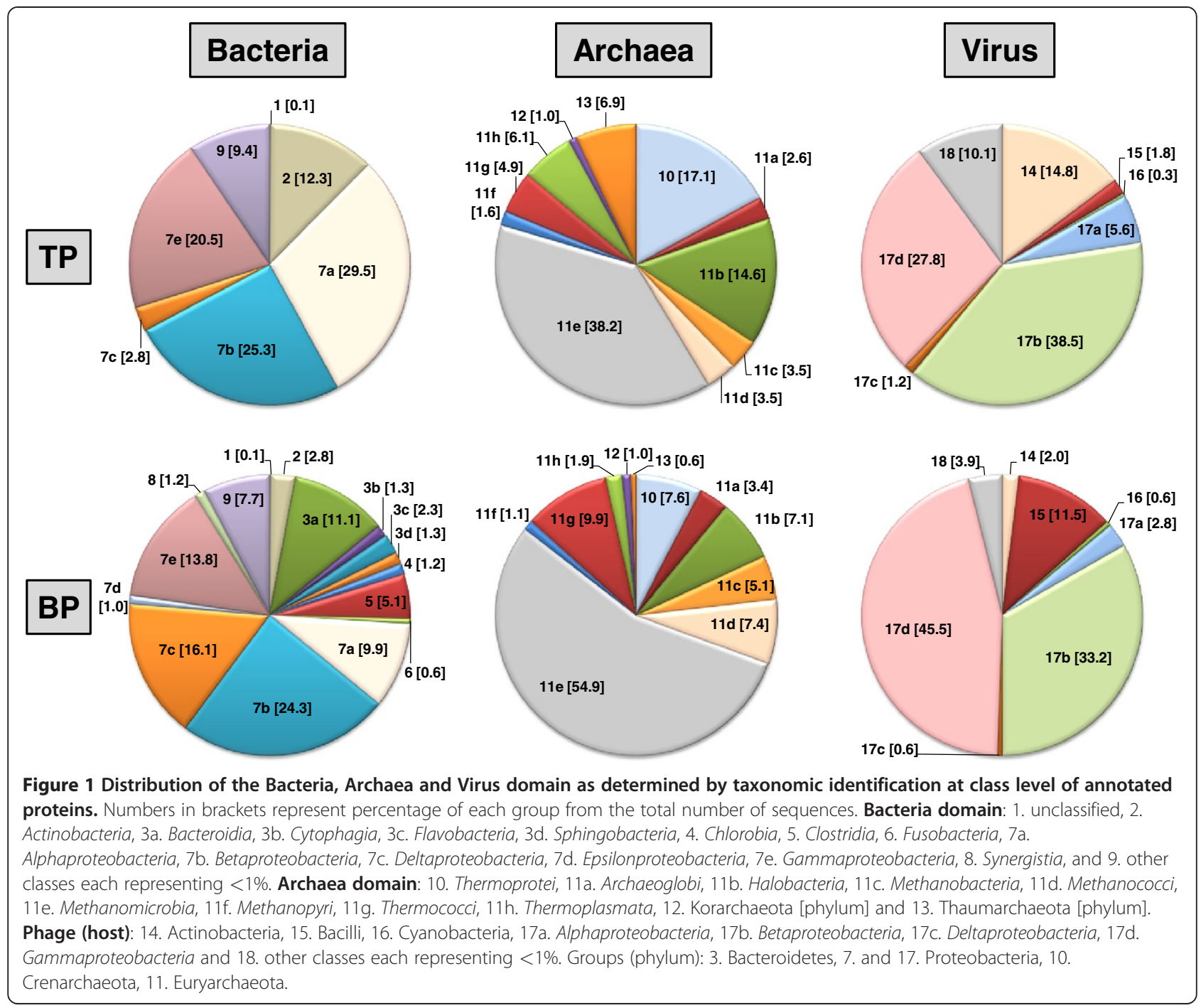

biofilm was dominated by the classes Methanomicrobia (55\%), Thermococcus (10\%) and Thermoprotei (8\%). The classes Methanomicrobia (38\%) and Thermoprotei (17\%) were also abundant in the TP site although Halobacteria (15\%) and Thaumarchaeota (7\%) were also abundant. Members of the Thaumarchaeota phylum are chemolithoautotrophic ammonia-oxidizers, which suggest that they may be playing a role in the nitrogen cycle in wastewater concrete biofilms [35]. Halobacteriales have been previously reported in wastewater sludge and may suggest the presence of alkaline hypersaline microenvironments in wastewater concrete biofilms [36]. The anaerobic niches in the wastewater pipe provide conditions for methanogenesis as suggested by the annotated sequences associated with genera such as Methanospirillum, Methanobrevibacter, Methanosphaera, Methanosaeta, Methanosarcina, and Methanococcoides [37]. However, the more favourable anaerobic conditions at the bottom of the pipe provide better conditions for this process. Indeed, there are a higher percentage of annotated sequences related to methanogenesis in the BP (69\%) than in TP metagenomes (47\%). Conversely, more methanotrophic and methylotrophic bacteria proteins were present in the TP (3.7\%) than in BP biofilm (1.8\%). Specifically, many of the sequences were related to proteins affiliated with Methylibium, Methylobacillus, Methylobacterium, Methylocella, Methylococcus, and Methylacidiphilum. The dominant annotated methaneoxidizing bacteria in the TP biofilm were affiliated with Methylocella silvestris, a moderately acidophilic $(\mathrm{pH}$ values between 4.5 and 7) and mesophilic species [38]. In general, our analysis identified microorganisms associated with one-carbon compound pathways (e.g. methanogenesis, methanotrophs and methylotrophs), although the importance of these metabolic processes in wastewater pipes remains unknown. 


\section{The role of biofilms in MICC}

Anaerobic conditions in wastewater collection systems support sulfate reducing bacteria (SRB) that convert sulfate and organic sulfides to $\mathrm{H}_{2} \mathrm{~S}$, which volatilizes to the sewer atmosphere and redissolves on the top of the pipe. The microbial community at the top oxidizes the sulfide to corrosive $\mathrm{H}_{2} \mathrm{SO}_{4}$ [39]. Consistent with this observation, analysis of $16 \mathrm{~S}$ rRNA gene clone libraries showed that the community structures differ, with a dominant presence in the BP of sulfate reducing bacteria (SRB) affiliated to Deltaproteobacteria. Specifically, there were 24 phylotypes represented by the genera Desulfobacter, Desulfobacterium, Desulfobulbus, Desulfomicrobium, Desulforegula and Desulfovibrio (Additional file 1, Figure S5). The predominant SRB phylotype $(5.4 \%)$ in the clone libraries is closely related to Desulfobacter postgatei, a strict anaerobic chemoorganotroph that completely oxidizes acetate to $\mathrm{CO}_{2}$ and reduces sulfur compounds (e.g. sulfate, sulfite, or thiosulfate) to $\mathrm{H}_{2} \mathrm{~S}$ [40]. In the TP sample, most SOB phylotypes (i.e., 39 of 45) are affiliated to the genus Thiobacillus (Betaproteobacteria) (Additional file 1, Figure S6), further supporting the importance of this group in concrete corrosion [41]. During the concrete corrosion process it has been shown that Thiobacillus thioparus, $T$. novellus, T. neapolitanus, and T. intermedius are involved in the initial and intermediate stages of colonization, while T. thiooxidans dominate in the final stage when the $\mathrm{pH}$ reaches values $<3$ [3]. In our study the majority of the Thiobacillus-like sequences were closely related to uncultured sulfur-oxidizing bacteria clones. Interestingly, two of the dominant clones in our libraries were identified as neutrophilic $T$. thioparus and $T$. plumbophilus (>98.5\% sequence identity) (Additional file 1, Figure S6). T. thioparus oxidizes sulfur and thiosulfate, reducing the medium between $\mathrm{pH} 3.5$ and 5 [3]. T. plumbophilus grows by oxidation of $\mathrm{H}_{2} \mathrm{~S}$ and $\mathrm{H}_{2}$ at $\mathrm{pH} 4$ and 6.5 [42]. There were also sequences with a high sequence homology (>99\%) to representatives of the Thiomonas intermedia and Acidiphilium acidophilum, members of the Beta- and Alphaproteobacteria class, respectively. $T$. intermedia is an obligate aerobe and facultative chemolithoautotroph that produces sulfuric acid at an optimum $\mathrm{pH}$ between 5 and 7 [43]. Thiomonas species are unable to denitrify or oxidize ferrous iron. In contrast, A. acidophilum is able to grow autotrophically or mixotrophically using sulfur or reduced inorganic sulfur compounds, as well as heterotrophically using various organic compounds and is capable of reducing iron [44].

Wastewater concrete corrosion involves the interaction of multiple groups and the establishment of these groups are driven by factors, such as the $\mathrm{pH}$ of the concrete, and the temporal dynamics of sulfur compounds [41]. The data from different studies conducted thus far suggest that the composition of species involved in concrete corrosion may vary within different wastewater systems. For instance, our study did not find any hyperacidophilic SOB sequences (e.g. T. thiooxidans, Acidithiobacillus thiooxidans) which had been previously detected in various MICC studies [39]. Okabe and colleagues [8] did not find T. thioparus, although $A$. acidophilum and T. plumbophilus were present at several stages of the MICC process. Altogether, molecular surveys strongly indicate that the dynamics of multiple microbial groups need to be studied in order to better develop condition assessment tools to monitor the performance of biocorrosion control measures.

\section{Comparative metagenome analysis}

Analysis of annotated COG (ChaoI and $S_{\mathrm{ACE}}: \approx 3932$ ) also showed that the wastewater biofilm samples are highly diverse. The level of COG diversity is similar to that described for whale fall $(3,332)$, soil $(3,394)$, and Sargasso Sea samples $(3,714)$, but higher than that described for acid mine drainage $(1,824)$ and human distal gut $(2,556)[24,45]$. Statistical tests based on COG categories or SEED subsystems found no significant difference in community richness between the BP and TP samples ( $t$-test, $p=0.156)$. The majority of the assigned genes in both metagenomes were identified as part of the SEED database Carbohydrate subsystem (Additional file 1, Figure S1) with sequences linked to $\mathrm{CO}_{2}$ fixation, Central Carbohydrate and Fermentation subsystems. In both biofilms the single most abundant component of the Carbohydrate subsystem was the TCA Cycle followed by the significant presence of common functions involved in Glycolysis and Gluconeogenesis, Photorespiration (oxidative $\mathrm{C} 2$ cycle), Pentose phosphate pathway, Entner-Doudoroff Pathway, Trehalose Biosynthesis and $\mathrm{CO}_{2}$ uptake. There were distinctive differences between the metagenomes in the Carbohydrate subsystem (Fisher's exact test, $q<0.05$ ). A significant number of sequences in the TP were associated with $\mathrm{CO}_{2}$ fixation and included $\mathrm{CO}_{2}$ uptake (carboxysome) and photorespiration (oxidative $\mathrm{C} 2$ cycle). Carboxysomes are microcompartments that enhance the fixation of $\mathrm{CO}_{2}$ by RuBisCO and are present in several chemoautotrophic bacteria, including sulfur bacteria, such as Thiobacillus denitrificans, T. intermedia, and A. ferrooxidans [46]. Most of the BP sequences shared homologies to known genes involved in pyruvate:ferredoxin oxidoreductase, lactose utilization, $\beta$-glucoside metabolism, mixed acid fermentation, organic acids utilization (e.g. lactate) and sugar alcohols utilization (e.g. ethanolamine and propanediol). Based on the functional metabolic profile, the data suggest that the community present in the BP is predominantly composed of anaerobic or facultative aerobic bacteria with a wide variety of metabolic functions 
(Additional file 1, Figure S1). A relative high number of sequences were associated with cell maintenance and structural functions such as cell division, cell wall and synthesis of DNA, RNA and proteins. Consistent with other environments, individual biochemical pathways (e.g. Nitrogen, Sulfur, Iron, Phosphorous and Potassium) comprised less than $1 \%$ of the functional genes profile $[47,48]$. Although functional similarities were observed, there were also relevant differences between the two biofilm samples. Most of the differences were attributed to the enrichment of specific gene families within metabolic pathways, some of which may indicate functional niches corresponding to varying microenvironments in the sewer pipes.

\section{Sulfur metabolism}

Analysis of metagenome libraries identified key genes implicated in the sulfur pathway (Figure 2). These functions were found to be abundant in the metagenomes, although we observed differences in the enrichment of specific gene families within the sulfur pathway. For example, in both metagenomes enzymes of three pathways involved in sulfur oxidation were detected: the Adenosine-5'-Phosphosulfate (EC 2.7.7.4, EC 1.8.99.2), the Sulfite:Cytochrome C oxidoreductase (EC 1.8.2.1) and the Sox enzyme complex (Figure 2). However, we found a relatively low odds ratio for the first pathway $(<1.5)$, while the enzymes of the Sox complex that convert thiosulfate to sulfate were more statistically abundant and enriched (odds ratio $>9$ ) in the TP biofilm
(Fisher's exact test, $q<0.05$ ) (Table 2, Figure 2). Approximately $66 \%$ of the genomes in TP metagenome contained the $\operatorname{sox} B$ gene, a key gene of the periplasmic Sox enzyme complex [49] (Table 2). The widespread distribution of the Sox-complex among various phylogenetic groups of SOB was confirmed [50], specifically soxB-sequences affiliated with $T$. intermedia, $T$. denitrificans, T. thioparus, Acidiphilium cryptum, and species of Burkholderia among others (Additional file 1, Figure S7). The relative similar level of enrichment of the Adenosine5'-Phosphosulfate pathway may be explained by the fact that key enzymes can be found in species of SRB and $\mathrm{SOB}$, in which the latter can operate in the reverse direction [51,52]. In addition, the composition of species carrying the $d s r B$ gene (sulfite reductase; EC 1.8.99.1) is noteworthy (Fisher's exact test, $q<0.05$ ) (Figure 2 and Table 2). Retrieved $d s r B$-sequences for the TP biofilm show $80 \%$ of genes were closely related to $T$. denitrificans (SOB), while $78 \%$ in the BP were represented by SRB: Desulfobacter postgatei, Desulfomicrobium baculatum, and species of Desulfovibrio among others (Additional file 1, Figure S7).

The wide range of annotated functions associated in several sulfur pathways may be indicative of the availability of several electron donors at wastewater pipes undergoing corrosion. While the role of some bacterial groups might be predicted based on previous studies, our study suggests that additional bacterial groups might be playing important roles within wastewater concrete corrosion processes. This is the case for SRB as they are

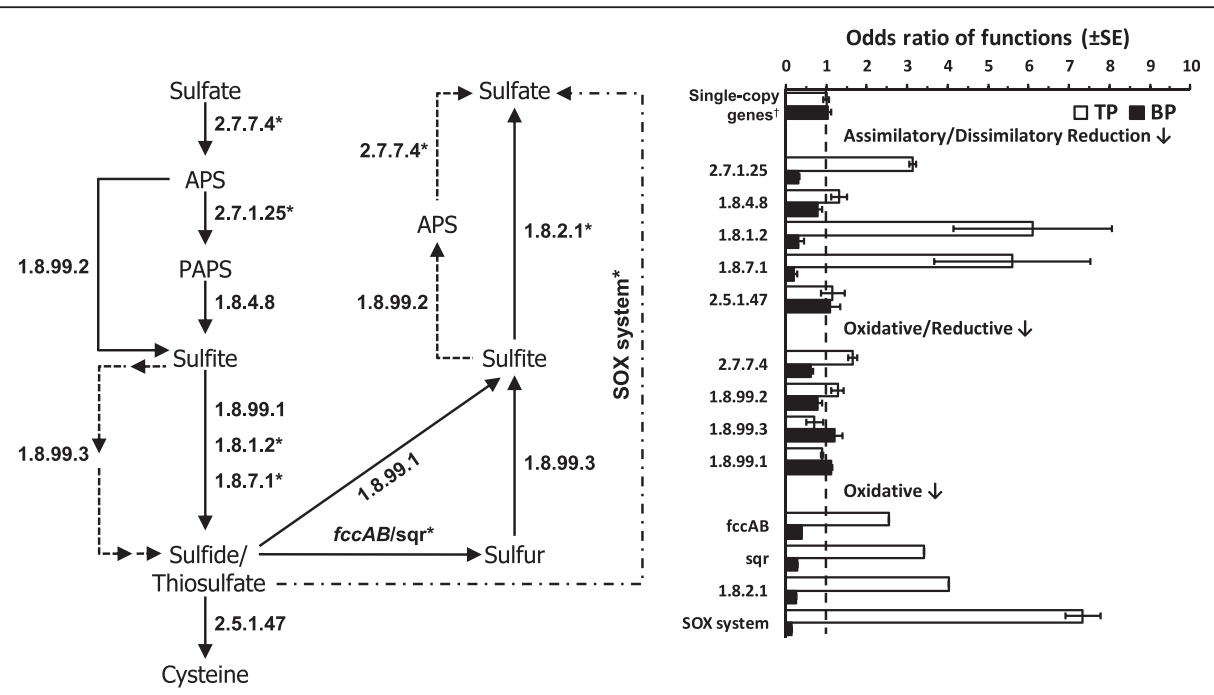

Figure 2 Enrichment of enzymes in the sulfur metabolic pathway. Diagram with the enzyme classification (identified by their Enzyme Commission number; EC number) for each step in the sulfur pathway. Asterik $\left(^{*}\right)$ indicate components that are significantly different between the two samples $(q<0.05)$ based on the Fisher's exact test using corrected $q$-values (Storey's FDR multiple test correction approach) (Table 2). Bar chart shows the odds ratio values for each function. An odds ratio of 1 indicates that the community DNA has the same proportion of hits to a given category as the comparison data set [24]. Housekeeping genes: gyrA, gyrB, recA, rpoA and rpoB. Error bars represent the standard error of the mean. 
Table 2 Estimation (\%) and enrichment of Sulfur and Nitrogen biochemical functional genes in wastewater genomes

\begin{tabular}{|c|c|c|c|c|c|c|c|}
\hline \multirow[t]{2}{*}{ Subsystem } & \multirow[t]{2}{*}{ Gene } & \multirow[t]{2}{*}{$n$} & \multicolumn{2}{|c|}{$\%$ of genomes with gene ${ }^{\dagger}$} & \multirow[t]{2}{*}{$q$-value* } & \multicolumn{2}{|c|}{ Odds ratio } \\
\hline & & & $\mathrm{TP}$ & BP & & TP/BP & $\mathrm{BP} / \mathrm{TP}$ \\
\hline Single-copy genes & & 5 & 100 & 100 & ns & 1.0 & 1.0 \\
\hline \multicolumn{8}{|l|}{ Sulfur metabolism } \\
\hline Sulfate adenylyltransferase (ATP) & cys $N$ & 1 & 54 & 33 & 0.000 & 1.6 & 0.6 \\
\hline Adenylyl-sulfate kinase & aspK & 1 & 52 & 15 & 0.000 & 3.2 & 0.3 \\
\hline Phosphoadenylyl-sulfate reductase & cysH & 1 & 26 & 22 & ns & 1.1 & 0.9 \\
\hline Adenylyl-sulfate reductase & aprA & 1 & 15 & 10 & ns & 1.4 & 0.7 \\
\hline $3^{\prime}\left(2^{\prime}\right), 5^{\prime}$-bisphosphate nucleotidase & cysQ & 1 & 67 & 40 & 0.000 & 1.6 & 0.6 \\
\hline Hydrogensulfite reductase & $d s r A$ & 1 & 13 & 15 & ns & 0.8 & 1.3 \\
\hline Sulfite reductase (NADPH) & cys」 & 1 & 28 & 4 & 0.000 & 7.6 & 0.1 \\
\hline Sulfite reductase (DSR) & $d s r B$ & 1 & 13 & 14 & ns & 1.0 & 1.0 \\
\hline Sulfite reductase (ferredoxin) & sir & 1 & 22 & 6 & 0.000 & 3.7 & 0.3 \\
\hline Cysteine synthase & cysk & 1 & $>100$ & $>100$ & ns & 1.0 & 1.0 \\
\hline Thiosulfate oxidise & $\operatorname{sox} B$ & 1 & 66 & 7 & 0.000 & 9.1 & 0.1 \\
\hline \multicolumn{8}{|l|}{ Nitrogen metabolism } \\
\hline Ammonia monooxygenase & $a m o A$ & 1 & 8 & 29 & 0.000 & 0.3 & 3.6 \\
\hline Nitrate reductase & napA & 1 & 2 & 13 & 0.000 & 0.1 & 8.0 \\
\hline Nitrate reductase & narG & 1 & 17 & 28 & 0.000 & 0.6 & 1.7 \\
\hline Nitrate reductase & nas $A$ & 1 & 68 & 34 & 0.000 & 2.0 & 0.5 \\
\hline Nitric oxide reductase & norB & 1 & 2 & 23 & 0.001 & 0.1 & 9.4 \\
\hline Nitric oxide reductase & qnor & 1 & 22 & 23 & ns & 1.0 & 1.0 \\
\hline Nitrite reductase & nirk & 1 & 17 & 3 & 0.000 & 5.2 & 0.2 \\
\hline Nitrite reductase & nirs & 1 & 2 & 30 & 0.000 & 0.1 & 16.4 \\
\hline Nitrous oxide reductase & $\operatorname{nos} Z$ & 1 & 10 & 35 & 0.030 & 0.3 & 3.6 \\
\hline Nitrite reductase & nirB & 1 & 64 & 44 & 0.000 & 1.4 & 0.7 \\
\hline Nitrite reductase & nirA & 1 & 7 & 1 & 0.018 & 5.6 & 0.2 \\
\hline Nitrite reductase & $n r f A$ & 1 & 1 & 45 & 0.000 & 0.0 & 58.4 \\
\hline Nitrogenase (molybdenum-iron) & nifD & 1 & 1 & 23 & 0.000 & 0.0 & 24.6 \\
\hline Nitrogenase (iron) & nifH & 1 & 15 & 23 & 0.006 & 0.6 & 1.6 \\
\hline
\end{tabular}

*Indicate components that are significantly different between the two samples $(q<0.05)$ based on the Fisher's exact test using corrected $q$-values (Storey's FDR multiple test correction approach).

tHousekeeping genes: $g y r A, g y r B, r e c A, r p o A$ and $r p o B$.

${ }^{\dagger}$ Direct comparison between the frequency of different functional genes, either within or between metagenomes, was not established since length and copy number of the gene was not incorporated in the formula.

$T P$ : top pipe.

$B P$ : bottom pipe.

$N S$ : not significant.

ND: not determine.

a phylogenetically diverse group that cannot be monitored using a single $16 \mathrm{~S}$ rRNA gene assay (Additional file 1, Figure S7). Our approach provides a sequencebased framework that can be used to monitor relevant microbial populations via function-specific assays. These assays can be used to measure the expression of key genes involved in corrosion processes, and hence be used to provide a condition assessment tool prior to corrosion processes that are irreversible.

\section{Nitrogen metabolism}

In spite of the importance of the nitrogen cycle in a wide range of habitats, the functional capabilities and distribution of their enzymes in wastewater systems, such as concrete biofilms, have not been fully explored. We identified key genes for nitrification, denitrification, nitrogen fixation and nitrate ammonification, including ammonia monooxygenase $(a m o A)$, nitrate reductase (narG, napA, nas A), nitrite reductase (nirK, nirS), nitric 
oxide reductase (nor), nitrous oxide reductase (nosZ), nitrogenase (nifH, nifD) and assimilatory nitrite reductase (nrfA, nirA, nirB) in both metagenomes (Figure 3). Differences in the distribution and taxonomic assignment of key genes involved in the nitrogen cycle were observed in our analysis (Table 2 and Additional file 1, Figure S8). Specifically, amoA, narG, napA, nirS and $n r f A$ were highly enriched in the BP sample, while there was a higher distribution of the nasA, nirK and nirB in the TP (Fisher's exact test, $q<0.05$ ). The majority of the sequences in the BP sample were annotated to species of Acidovorax, Thauera and Deltaproteobacteria (i.e. SRB), while most of the genes in the TP were associated with members of the T. intermedia, T. denitrificans, and species of Burkholderia among others (Additional file 1, Figure S8). Differences in the distribution and functional capability may be associated with the availability of oxygen and concentration of $\mathrm{N}$ compounds at each environment. Respiratory nitrate reductase (narG) reduces nitrate to nitrite predominantly during anaerobic growth, while the nas $A$ assimilate nitrate during aerobic growth [53]. Furthermore, the enrichment of nirS, nor, and nos $Z$ suggest that the majority of the nitrite in the $\mathrm{BP}$ biofilm is reduced preferentially through the denitrification pathway (Figure 3). The $n r f A$ enzyme is highly enriched at the BP biofilm (Fisher's exact test, $q<0.05$ ) (Figure 3 and Table 2), supporting the observation that the $n r f A$ enzyme is expressed when nitrate (or nitrite) is limiting in the environment [54]. On the other hand, we observed an enrichment of the nirB at the TP biofilm (Fisher's exact test, $q<0.05$ ) (Figure 3 and Table 2), which is expressed only when nitrate or nitrite is in excess in the environment [54]. The enrichment of nitrification genes in the BP may be explained by the fact that domestic wastewater carry a substantial concentration of nitrogen compounds (20 to $70 \mathrm{mg} / \mathrm{L}$ ), consisting of $60-70 \% \mathrm{NH}_{3}-\mathrm{N}$ and $30-40 \%$ organic $\mathrm{N}$ [55]. In fact, the gene encoding for ammonia monooxygenase $(a m o A)$, a key enzyme for ammonia oxidation was highly enriched in the BP metagenome (Fisher's exact test, $q<0.05$ ) (Table 2). The metagenome data suggest that habitat prevailing conditions can select for bacterial populations with functionally equivalent yet ecologically nonredundant genes [56]. Specifically, we noted nirK is enriched in the TP while the nirS (nitrite reductase) is more prevalent in the BP biofilm (Fisher's exact test, $q<$ $0.05)$.

\section{Functional diversity}

We detected the presence of several types of adaptive responses to various heavy metal ions with the majority of the heavy metal-related functions enriched in the TP biofilms where the acid conditions are prevalent (Table 3). The majority of heavy metals become more soluble and mobile under low $\mathrm{pH}$ conditions [57]. It also appears that TP and BP biofilms are dominated by different types of uptake systems to control the intracellular concentration of heavy metal ions: (1) a fast, unspecific and constitutively expressed system and (2) an ATP hydrolysis-dependent slower yet highly specific system [58]. For example, the stand-alone arsB chemiosmotic transport protein (i.e. anion channel) is enriched in the

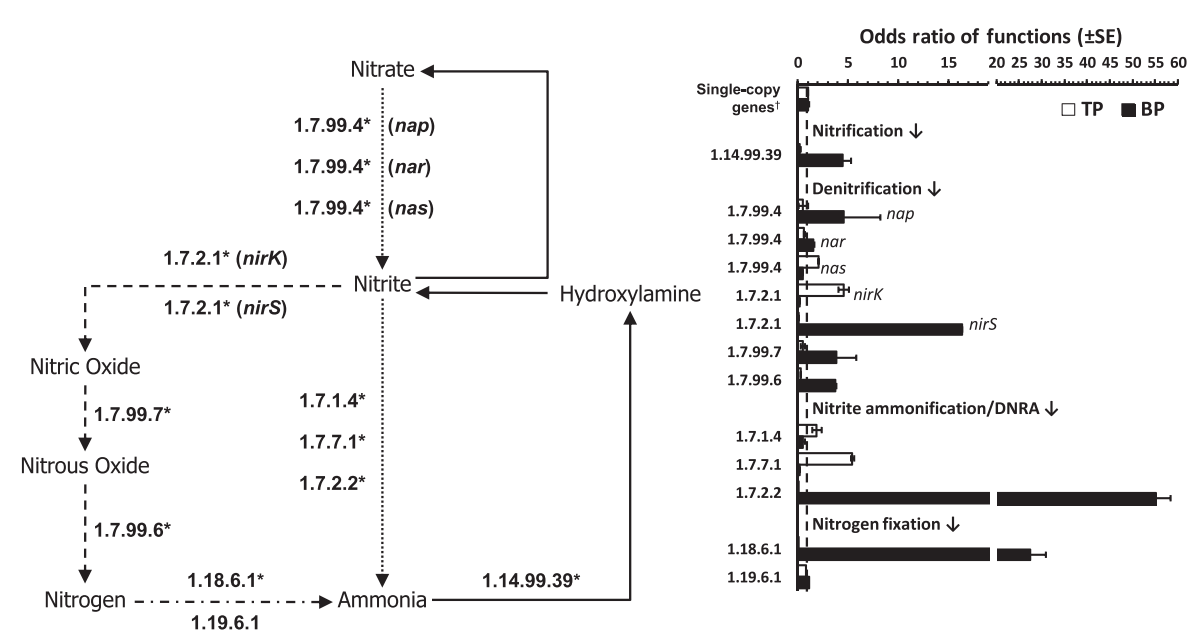

Figure 3 Enrichment of enzymes in the nitrogen metabolic pathway. Diagram with the enzyme classification (identified by their Enzyme Commission number; EC number) for each step in the nitrogen pathway. Asterik $\left(^{*}\right)$ indicate components that are significantly different between the two samples $(q<0.05)$ based on the Fisher's exact test using corrected $q$-values (Storey's FDR multiple test correction approach) (Table 2). Bar chart shows the odds ratio values for each function. An odds ratio of 1 indicates that the community DNA has the same proportion of hits to a given category as the comparison data set [24]. Housekeeping genes: $g y r A, g y r B$, recA, rpoA and rpoB. Error bars represent the standard error of the mean. 
Table 3 Estimation (\%) and enrichment of motility, stress, antibiotics and toxic resistance genes in wastewater genomes

\begin{tabular}{|c|c|c|c|c|c|c|c|}
\hline \multirow[t]{2}{*}{ Subsystem } & \multirow[t]{2}{*}{ Gene } & \multirow[t]{2}{*}{$n$} & \multicolumn{2}{|c|}{$\%$ of genomes with gene ${ }^{\dagger}$} & \multirow[t]{2}{*}{$q$-value* } & \multicolumn{2}{|c|}{ Odds ratio } \\
\hline & & & $\overline{T P}$ & BP & & TP/BP & $\mathrm{BP} / \mathrm{TP}$ \\
\hline Single-copy genes & & 5 & 100 & 100 & ns & 1.0 & 1.0 \\
\hline \multicolumn{8}{|l|}{ Heavy metal resistance } \\
\hline Arsenate reductase (glutaredoxin) & $\operatorname{arsC}$ & 1 & 50 & 17 & 0.000 & 2.8 & 0.4 \\
\hline Arsenic efflux pump protein & $\operatorname{ars} B$ & 1 & 24 & 10 & 0.000 & 2.4 & 0.4 \\
\hline Arsenic resistance protein & arsH & 1 & 37 & 5 & 0.000 & 7.4 & 0.1 \\
\hline Arsenical pump-driving (ATPase) & $\operatorname{ars} A$ & 1 & 15 & 28 & 0.000 & 0.5 & 1.9 \\
\hline Arsenite oxidase & $a \circ \times B$ & 1 & 10 & 8 & ns & 1.3 & 0.8 \\
\hline Cadmium-transporting (ATPase) & $\operatorname{cad} A$ & 1 & 3 & 14 & 0.000 & 0.2 & 4.5 \\
\hline Chromate transport protein & chrA & 1 & 40 & 50 & 0.034 & 0.8 & 1.3 \\
\hline Copper-translocating P-type (ATPase) & copA & 1 & $>100$ & $>100$ & ns & 1.1 & 0.9 \\
\hline CZC resistance protein & $c z c D$ & 1 & $>100$ & 75 & 0.006 & 1.6 & 0.6 \\
\hline Mercuric reductase & merA & 1 & 80 & 33 & 0.000 & 2.4 & 0.4 \\
\hline \multicolumn{8}{|l|}{ Antibiotics \& toxicity resistance } \\
\hline Beta-lactamase & $a m p C$ & 1 & $>100$ & $>100$ & 0.000 & 1.8 & 0.6 \\
\hline Beta-lactamase (MRSA) & mecA & 1 & 0 & 0 & nd & 0 & 0 \\
\hline Dihydrofolate reductase & folA & 1 & 80 & 47 & 0.034 & 1.6 & 0.6 \\
\hline Pterin binding enzyme & sul & 1 & 83 & 66 & 0.003 & 1.3 & 0.8 \\
\hline Multidrug efflux system protein & $a c r B$ & 1 & $>100$ & $>100$ & 0.000 & 1.4 & 0.7 \\
\hline Dioxygenase (Bleomycin resistance) & bleO & 1 & $>100$ & $>100$ & 0.000 & 2.3 & 0.4 \\
\hline Aminoglycoside-3'-adenylyltransferase & $\operatorname{aadA}$ & 1 & 40 & $>100$ & 0.000 & 0.3 & 3.2 \\
\hline Antiholin-like protein (murein hydrolase) & $\operatorname{lrg} A$ & 1 & 4 & 37 & 0.000 & 0.1 & 9.6 \\
\hline Antiholin-like protein (murein hydrolase) & $\operatorname{lrg} B$ & 1 & 17 & 39 & 0.001 & 0.4 & 2.5 \\
\hline Streptomycin adenylyltransferase & ant1 & 1 & 0 & 3 & 0.031 & 0.0 & nd \\
\hline Drug resistance transporter & $C f / A$ & 1 & 61 & 37 & 0.000 & 1.6 & 0.6 \\
\hline MFS transporter (DHA2) & emrB & 1 & $>100$ & 57 & 0.000 & 3.6 & 0.3 \\
\hline D-alanine-D-alanine ligase & $\operatorname{vanA}$ & 1 & 76 & 81 & ns & 0.9 & 1.1 \\
\hline Multi antimicrobial extrusion protein & norM & 1 & 6 & 40 & 0.000 & 0.2 & 6.6 \\
\hline Multidrug efflux transporter & $\operatorname{mexF}$ & 1 & 16 & 6 & 0.043 & 2.7 & 0.4 \\
\hline RND efflux system (transporter) & cmeB & 1 & 53 & $>100$ & 0.000 & 0.5 & 2.1 \\
\hline RND efflux system (membrane protein) & cmeA & 1 & 18 & 46 & 0.005 & 0.4 & 2.5 \\
\hline RND efflux system (lipoprotein) & cmeC & 1 & 19 & 60 & 0.020 & 0.3 & 3.1 \\
\hline \multicolumn{8}{|l|}{ Protein secretion systems } \\
\hline Type I & - & 1 & nd & nd & 0.000 & 1.5 & 0.7 \\
\hline Type III & - & 10 & nd & nd & 0.001 & 0.8 & 1.8 \\
\hline Type IV & - & 5 & nd & nd & 0.000 & 3.1 & 1.4 \\
\hline Type V & - & 3 & nd & nd & 0.001 & 1.7 & 0.6 \\
\hline Type VI & - & 10 & nd & nd & 0.000 & 2.8 & 0.7 \\
\hline \multicolumn{8}{|l|}{ Motility \& Chemotaxis systems } \\
\hline motility/chemotaxis & - & 74 & nd & nd & 0.000 & 0.7 & 2.7 \\
\hline \multicolumn{8}{|l|}{ Stress systems } \\
\hline stress response & - & 276 & nd & nd & 0.000 & 2.2 & 1.8 \\
\hline
\end{tabular}

*Indicate components that are significantly different between the two samples $(q<0.05)$ based on the Fisher's exact test using corrected $q$-values (Storey's FDR multiple test correction approach).

Housekeeping genes: $g y r A$, gyrB, rec $A, r p o A$ and $r p o B$

${ }^{\dagger}$ Direct comparison between the frequency of different functional genes, either within or between metagenomes, was not established since length and copy number of the gene was not incorporated in the formula.

TP: top pipe.

$B P$ : bottom pipe.

$N S$ : not significant.

ND: not determine. 
TP biofilm (Fisher's exact test, $q<0.05$ ), while the BP biofilm is rich in arsA enzymes (EC 3.6.3.16) (Fisher's exact test, $q<0.05$ ), which transform the ars $B$ into an $\operatorname{ars} A B$ ATPase complex [59]. The presence of heavy metal compounds provide the opportunity for selected individuals to oxidize these substrates and generate energy, as is the case of the presence of Thiomonas spp. with $a 0 x B$ arsenite oxidase genes (EC 1.20.98.1) [60].

A high number of genes associated with motility, stress response, antibiotic resistance, and virulence (e.g. efflux pump) were also identified in this study (Table 3). Motility and chemotaxis related functions seem to be important properties for submerged environments, such as the BP site, enabling bacteria to rapidly colonize surfaces through biofilm formation [61] and to respond to changes in environmental conditions characteristic of wastewater habitats [62]. In extreme and rapidly changing habitats, such as corroded concrete structures, microorganisms must respond with appropriate gene expression and protein activity [63]. We detected the enrichment of stress response components at the TP, which is characterized by the low $\mathrm{pH}$ of the surface and temporal changes in heavy metal ions due to corrosion (Table 3). Both biofilms have a high distribution of genes related to antibiotic resistance with a significant percentage of the genes incorporated in their genomes (Table 3). Furthermore, the wastewater biofilms contained an abundance of virulence-associated protein secretion systems, representing a reservoir for virulence genes. This may represent a conservative estimate of the number of potential virulence factors, since we only screened for a subset of genes homologous to type I, IV, V and VI secretion systems [64]. The significant number of resistance and virulence genes in their genomes and distribution based on odds-ratio (i.e. enrichment) analysis is consistent with the idea that sewage systems harbor favorable conditions for the establishment and propagation of antibiotic resistant bacteria [65].

Metagenomic data generated in this study enabled us to detect, identify and reconstruct metabolic pathways involved in MICC. The information generated from these sequencing libraries will help us better understand the genetic network and microbial members involved in wastewater biofilms. This information is also relevant to track microbial populations associated with concrete biofilms and to evaluate molecular assays used to detect key functional genes. In a recent study, Santo Domingo and colleagues [11] failed to detect the presence of ammonia oxidizing bacteria (AOB) on wastewater concrete biofilms using amoA-based PCR assays. These bacteria are expected to be associated with wastewater systems. In this study we were able to detect the presence of putative membrane-associated ammonia monooxygenase in the BP biofilm. The metagenomic sequences were highly homologous to sequences from heterotrophic representatives of the species Acidovorax delafieldii, Thauera sp MZ1T and species of Rhizobiales (Additional file 1, Figure S8). Heterotrophic ammonia oxidizing bacteria are commonly found in wastewater systems [66]. Ammonia oxidation by heterotrophic bacteria usually does not involve the generation of energy and is probably used as a sink for excess reducing power generated by oxidative metabolism [67]. Thus, the lack of previous detection of amoA genes by Santo Domingo et al. [11] can be explained by the fact that the assay cannot detect the $a m o A$ in heterotrophic ammonia oxidizing bacteria as they were designed to amplify representatives of the autotrophic ammonia monooxygenase, for example, Nitrosomonas species [68]. On the other hand, this study confirmed the validity of the $\operatorname{sox} B$ PCR-based assay to detect the presence of thiosulfate-oxidizing Sox enzyme complex in wastewater concrete [11]. A high percentage (>90\%) of our metagenome sequences belong to species that contain the region for the Sox primers designed by Petri and colleagues [69], suggesting that they can be used to ascertain the presence of SOB in this environment.

In wastewater collection systems the sulfur and nitrogen pathways play an important role in MICC, and the populations engaged in these pathways are part of a complex and highly diverse microbial community [39]. The reconstruction of the sulfur metabolism network showed several pathways used to oxidize the end products of sulfate reduction leading to the production of $\mathrm{H}_{2} \mathrm{SO}_{4}$, e.g. Sox complex, sulfide quinone oxidoreductase $(s q r)$ and the flavocytochrome $c(f c c A B)$ in the corroded section of the pipe (Figure 2). We detected similar levels of enrichment in both biofilms of the $d s r B$ enzyme (Table 3). On the basis of these observations, and to better understand and control MICC, future investigations must consider the ability of these communities to: (1) utilize different sulfur compounds, e.g. thiosulfate (Sox complex) or sulfide (sqr, $f c c A B$ ), (2) adapt to temporal variation in the concentrations of sulfide, e.g. low sulfide $(s q r)$ and high sulfide $(f c c A B)$, and (3) reverse the action of their enzymes, e.g. $d s r B$ involves both the oxidative and the reductive mode of the dissimilatory sulfur metabolism. Sequences obtained in this study provide the molecular framework to detect the populations carrying relevant functions in future monitoring studies (Additional file 1, Figures S7 and S8).

Recently safe and cost-effective approaches to inhibit or prevent corrosion have included influencing the microbial population without the application of biocides by (1) supporting the establishment of competitive biofilms and (2) removing or adding electron acceptors such as nitrate $[5,70]$. The addition of nitrate can stimulate the growth of competing bacterial populations (e.g. nitratereducing bacteria), which can effectively displace the 
SRB [71]. The success of these approaches must include a detailed analysis of the established bacterial populations and functional capabilities of the microbial community in that particular system. In fact, our data provide evidence of the effect of habitat selective factors on microorganisms and consequently their functional capabilities. For example, the diversity of the denitrification genes nirK and nirS increased in habitats with relatively moderate and low levels of nitrate/nitrite, respectively [72]. Other corrosion control approaches include commercially available coating techniques, for which limited data is available on their performance. The data from this study identified the potential bacterial groups and specific gene sequences that remediation approaches need to target to prevent microbial colonization of key concrete corrosion-associated microbiota.

\section{Conclusions}

In the present work, we analyzed wastewater concrete metagenomic and phylogenetic sequences in an effort to better understand the composition and function potential of concrete biofilms. The analyses unveiled novel insights on the molecular ecology and genetic function potential of concrete biofilms. These communities are highly diverse and harbor complex genetic networks, mostly composed of bacteria, although archaeal and viral (e.g., phages) sequences were identified as well. In particular, we provided insights on the bacterial populations associated with the sulfur and nitrogen cycle, which may be directly or indirectly implicated in concrete corrosion. By identifying gene sequences associated with them, their potential role in the corrosion of concrete can be further studied using multiple genetic assays. The development of comprehensive databases such as the one generated in this study as well as for microbial communities in wastewater systems with a wide range of corrosion conditions will be useful in the development of tools in diagnosing and preventing MICC. Although the emphasis of this study was on corrosion processes, we also identified the presence of bacterial virulence factors and antibiotic resistance genes, suggesting that these systems are reservoirs of microbial populations of public health relevance.

\section{Additional file}

Additional file 1: Figure S1. Distribution (\%) of sequences identified to particular subsystems (SEED) in metagenomes of wastewater biofilms. Figure S2. Distribution of bacterial classes on concrete wastewater pipes as determined by taxonomic identification of 165 rRNA genes recovered from metagenome libraries. Numbers in brackets represent percentage of each group from the total number of sequences. Legend: 1. unclassified Bacteria domain, 2. Actinobacteria, 3a. Bacteroidia, 3b. Flavobacteria, 3c. Sphingobacteria, 4. Chloroflexi, 5a. Bacilli, 5b. Clostridia, 6. Fusobacteria, 7a. Alphaproteobacteria, 7b. Betaproteobacteria, 7c.

Deltaproteobacteria, 7d. Epsilonproteobacteria, 7e. Gammaproteobacteria
8. Synergistia and 9. other classes each representing $<1 \%$. Groups (phylum): 3. Bacteroidetes, 5. Firmicutes, 7. Proteobacteria . Figure S3. UPGMA cluster analysis of Bray-Curtis similarity coefficients for biofilms in wastewater systems. Sample types were classified by their taxonomic dominant group within the sulfur biogeochemical cycle: sulfur-reducing bacteria (SRB) and sulfur/sulfide-oxidizing bacteria (SOB). Location of biofilm: bottom (a), middle (b), top (c) and outdoor (d). Figure S4.

Phylogenetic affiliation of phylotypes identified as Bacteroidetes from each biofilm: top pipe (TP, gray) and bottom pipe (BP, black). Clones were identified by genus or order $\left(^{*}\right)$ and percentage of each representative sequence in their respective libraries is provided in the brackets. The tree was inferred using maximum likelihood analysis of aligned 16S rRNA gene sequences with bootstrap values from 100 replicates. Box indicates the two most dominant phylotypes. Figure S5. Phylogenetic affiliation of Deltaproteobacteria phylotypes identified as sulfate-reducing bacteria (SRB) from each biofilm: top pipe (TP, gray) and bottom pipe (BP, black). Clones were identified by genus or family $\left(^{*}\right)$ and percentage of each representative sequence in their respective libraries is provided in the brackets. The tree was inferred using maximum likelihood analysis of aligned $16 \mathrm{~S}$ rRNA gene sequences with bootstrap values from 100 replicates. Box indicates dominant phylotype. Figure S6. Phylogenetic affiliation of the top 20 most abundant Proteobacteria phylotypes identified as sulfur/sulfide-oxidizing bacteria (SOB) from each biofilm: top pipe (TP, gray) and bottom pipe (BP, black). Clones were identified by genus (*family) and percentage of each representative sequence in their respective libraries is provided in the brackets. The tree was inferred using maximum likelihood analysis of aligned 165 rRNA gene sequences with bootstrap values from 100 replicates. Box indicates dominant phylotype Figure S7. Relative abundance of taxonomic groups based on MEGAN analysis of protein families associated with the sulfur pathway. Each circle is scaled logarithmically to represent the number of reads that were assigned to each taxonomic group. Wastewater biofilms: top pipe (TP, white) and bottom pipe (BP, black). EC = Enzyme

Commission number. Figure S8. Relative abundance of taxonomic groups based on MEGAN analysis of protein families associated with the nitrogen pathway. Each circle is scaled logarithmically to represent the number of reads that were assigned to each taxonomic group. Wastewater biofilms: top pipe (TP, white) and bottom pipe (BP, black). EC = Enzyme Commission number.

\section{Acknowledgements}

We thank Jarissa Garcia, John Sullivan, and James Weast of the Metropolitan Sewer District of Greater Cincinnati for the technical support provided during the collection of samples, to Dan Murray (USEPA) for discussions on concrete corrosion, to Brandon Iker for laboratory technical support, and to Robin Matlib for bioinformatics support. This manuscript was approved for publication by the United States Environmental Protection Agency (USEPA). Any opinions expressed in this manuscript are of the authors and do not necessarily reflect the official positions and policies of USEPA. Any mention of products or trade names does not constitute endorsement or recommendation for use.

\section{Authors' contributions}

VGA participated in bioinformatic and statistical analyses. RPR and JSD carried out sample collection and sample processing. RPR and JSD participated in design and coordination of the study. JSD conceived of the study. All authors helped to draft and revise the manuscript. All authors read and approved the final manuscript.

Received: 19 December 2011 Accepted: 22 June 2012

Published: 22 June 2012

\section{References}

1. USEPA (United States Environmental Protection Agency): State of Technology Review Report on Rehabilitation of Wastewater Collection and Water Distribution Systems. EPA/600/R-09/048. Cincinnati, OH: Office of Research and Development; 2009.

2. USEPA (United States Environmental Protection Agency): Wastewater collection system infrastructure research needs. EPA/600/JA-02/226. Edison, NJ: USEPA Urban Watershed Management Branch; 2002. 
3. Mori T, Nonaka T, Tazaki K, Koga M, Hikosaka $Y$, Noda S: Interactions of nutrients, moisture, and $\mathrm{pH}$ on microbial corrosion of concrete sewer pipes. Water Res 1992, 26:29-37.

4. Vollertsen J, Nielsen AH, Jensen HS, Wium-Andersen T, Hvitved-Jacobsen T: Corrosion of concrete sewers-the kinetics of hydrogen sulfide oxidation. Sci Total Environ 2008, 394:162-170.

5. Zhang L, De Schryver P, De Gusseme B, De Muynck W, Boon N, Verstraete $\mathrm{W}$ : Chemical and biological technologies for hydrogen sulfide emission control in sewer systems: a review. Water Res 2008, 42:1-12.

6. Vincke $E$, Boon N, Verstraete W: Analysis of the microbial communities on corroded concrete sewer pipes - a case study. App/ Microbiol Biotechnol 2001, 57:776-785.

7. Okabe S, Ito T, Satoh H: Sulfate-reducing bacterial community structure and their contribution to carbon mineralization in a wastewater biofilm growing under microaerophilic conditions. Appl Microbiol Biotechnol 2003, 63:322-334.

8. Okabe $\mathrm{S}$, Odagiri M, Ito T, Satoh H: Succession of sulfur-oxidizing bacteria in the microbial community on corroding concrete in sewer systems. Appl Environ Microbiol 2007, 73:971-980.

9. Satoh $\mathrm{H}$, Odagiri $\mathrm{M}$, Ito $\mathrm{T}$, Okabe $\mathrm{S}$ : Microbial community structures and in situ sulfate-reducing and sulfur-oxidizing activities in biofilms developed on mortar specimens in a corroded sewer system. Water Res 2009, 43:4729-4739.

10. Giannantonio DJ, Kurth JC, Kurtis KE, Sobecky PA: Molecular characterizations of microbial communities fouling painted and unpainted concrete structures. Int Biodeterior Biodegrad 2009, 63:30-40.

11. Santo Domingo JW, Revetta RP, Iker B, Gomez-Alvarez V, Garcia J, Sullivan J, Weast J: Molecular survey of concrete sewer biofilm microbial communities. Biofouling 2011, 27:993-1001.

12. Tamura K, Nei M, Kumar S: Prospects for inferring very large phylogenies by using the neighbor-joining method. Proc Natl Acad Sci USA 2004, 101:11030-11035.

13. Tamura K, Peterson D, Peterson N, Stecher G, Nei M, Kumar S: MEGA5: Molecular Evolutionary Genetics Analysis using maximum likelihood, evolutionary distance, and maximum parsimony methods. Mol Biol Evol 2011, 28:2731-2739

14. Cole JR, Wang Q, Cardenas E, Fish J, Chai B, Farris RJ1, Kulam-SyedMohideen AS, McGarrell DM, Marsh T, Garrity GM, Tiedje JM: The Ribosomal Database Project: improved alignments and new tools for rRNA analysis. Nucleic Acids Res 2009, 37:D141-D145.

15. Altschul SF, Madden TL, Schaffer AA, Zhang J, Zhang Z, Miller W, Lipman DJ: Gapped BLAST and PSI-BLAST: a new generation of protein database search programs. Nucleic Acids Res 1997, 25:3389-3402

16. Hammer $\varnothing$, Harper DAT, Ryan PD: PAST: paleontological statistics software package for evolution and data analysis. Palaeontol Electron 2001, 4:1-9.

17. Gomez-Alvarez V, Teal TK, Schmidt TM: Systematic artifacts in metagenomes from complex microbial communities. ISME J 2009, 3:1314-1317.

18. Meyer F, Paarmann D, D'Souza M, Olson R, Glass EM, Kubal M, Paczian T, Rodriguez A, Stevens R, Wilke A, Wilkening J, Edwards RA: The metagenomics RAST server - a public resource for the automatic phylogenetic and functional analysis of metagenomes. BMC Bioinforma 2008, 9:386-394.

19. Li W: Analysis and comparison of very large metagenomes with fast clustering and functional annotation. BMC Bioinforma 2009, 10:359-367.

20. Beszteri B, Temperton B, Frickenhaus S, Giovannoni SJ: Average genome size: a potential source of bias in comparative metagenomics. ISME J 2010, 4:1075-1077.

21. Raes J, Korbel JO, Lercher MJ, von Mering C, Bork P: Prediction of effective genome size in metagenomic samples. Genome Biol 2007, 8:R10.

22. Chao A, Shen TJ: SPADE (Species Prediction and Diversity Estimation) V2.1. Program and User's Guide. http://chao.stat.nthu.edu.tw.

23. Frank JA, Sørensen SJ: Quantitative metagenomic analyses based on average genome size normalization. Appl Environ Microbiol 2011 77:2513-2521.

24. Gill SR, Pop M, Deboy RT, Eckburg PB, Turnbaugh PJ, Samuel BS, Gordon II, Relman DA, Fraser-Liggett CM, Nelson KE: Metagenomic analysis of the human distal gut microbiome. Science 2006, 312:1355-1359.

25. Parks DH, Beiko RG: Identifying biologically relevant differences between metagenomic communities. Bioinformatics 2010, 26:715-721.
26. Sun S, Chen J, Li W, Altintas I, Lin A, Peltier S, Stocks K, Allen EE, Ellisman M Grethe J, Wooley J: Community cyberinfrastructure for Advanced Microbial Ecology Research and Analysis: the CAMERA resource. Nucleic Acids Res 2011, 39:D546-D551.

27. Huson DH, Mitra S, Ruscheweyh H-J, Weber N, Schuster SC: Integrative analysis of environmental sequences using MEGAN 4. Genome Res 2011, 21:1552-1560

28. Frias-Lopez J, Shi Y, Tyson GW, Coleman ML, Schuster SC, Chisholm SW, Delong EF: Microbial community gene expression in ocean surface waters. Proc Natl Acad Sci 2008, 105:3805-3810.

29. Urich T, Lanzén A, Qi J, Huson DH, Schleper C, Schuster SC: Simultaneous assessment of soil microbial community structure and function through analysis of the meta-transcriptome. PLoS One 2008, 3:e2527.

30. Poroyko V, White JR, Wang M, Donovan S, Alverdy J, Liu DC, Morowitz MJ: Gut microbial gene expression in mother-fed and formula-fed piglets. PLoS One 2010, 5:e12459.

31. Antonopoulos DA, Glass EM, Meyer F: Analyzing Metagenomic Data: Inferring Microbial Community Function with MG-RAST. In Metagenomics and its Applications in Agriculture, Biomedicine and Environmental Studies. Edited by Li RW. New York: Nova Publishers; 2011:Ch 3.

32. Weinbauer MG: Ecology of prokaryotic viruses. FEMS Microbiol Rev 2004 28:127-181.

33. Weinbauer $M G$, Rassoulzadegan F: Are viruses driving microbial diversification and diversity? Environ Microbiol 2004, 6:1-11.

34. Lin C, Miller TL: Phylogenetic analysis of Methanobrevibacter isolated from feces of humans and other animals. Arch Microbiol 1998, 169:397-403.

35. Brochier-Armanet C, Boussau B, Gribaldo S, Forterre P: Mesophilic Crenarchaeota: proposal for a third archaeal phylum, the Thaumarchaeota. Nat Rev Microbiol 2008, 6:245-252.

36. Williams D, Brown JW: Archaeal diversity in a municipal wastewater sludge. KBM J Biol 2010, 1:30-33.

37. Bapteste $E$, Brochier C, Boucher Y: Higher-level classification of the Archaea: evolution of methanogenesis and methanogens. Archaea 2005, 1:353-363.

38. Dunfield PF, Khmelenina VN, Suzina NE, Trotsenko YA, Dedysh SN: Methylocella silvestris sp. nov., a novel methanotroph isolated from an acidic forest cambisol. Int J Syst Evol Microbiol 2003, 53:1231-1239.

39. Little BJ, Ray Rl, Pope RK: Relationship between corrosion and the biological sulfur cycle: a review. Corrosion 2000, 56:433-443.

40. Widdel F, Pfennig N: Studies on dissimilatory sulfate-reducing bacteria that decompose fatty acids. I. Isolation of new sulfate-reducing bacteria enriched with acetate from saline environments. Description of Desulfobacter postgatei gen. nov., sp. nov. Arch Microbiol 1981, 129:395-400.

41. Roberts DJ, Nicaa D, Zuoa G, Davis JL: Quantifying microbially induced deterioration of concrete: initial studies. Int Biodeter Biodegr 2002, 49:227-234.

42. Drobner E, Huber H, Rachel R, Stetter KO: Thiobacillus plumbophilus spec. nov., a novel galena and hydrogen oxidizer. Arch Microbiol 1992, 157:213-217.

43. Moreira D, Amils R: Phylogeny of Thiobacillus cuprinus and other mixotrophic thiobacilli: proposal for Thiomonas gen. nov. Int J Syst Bacteriol 1997, 47:522-528.

44. Johnson DB, Bridge TA: Reduction of ferric iron by acidophilic heterotrophic bacteria: evidence for constitutive and inducible enzyme systems in Acidiphilium spp. J Appl Microbiol 2002, 92:315-321.

45. Tringe SG, von Mering C, Kobayashi A, Salamov AA, Chen K, Chang HW, Podar M, Short JM, Mathur EJ, Detter JC, Bork P, Hugenholtz P, Rubin EM: Comparative metagenomics of microbial communities. Science 2005 308:554-557.

46. Cannon GC, Baker SH, Soyer F, Johnson DR, Bradburne CE, Mehlman JL, Davies PS, Jiang QL, Heinhorst S, Shively JM: Organization of carboxysome genes in the thiobacilli. Curr Microbiol 2003, 46:115-119.

47. Dinsdale EA, Edwards RA, Hall D, Angly F, Breitbart M, Brulc JM, Furlan M, Desnues C, Haynes M, Li L, McDaniel L, Moran MA, Nelson KE, Nilsson C, Olson R, Paul J, Brito BR, Ruan Y, Swan BK, Stevens R, Valentine DL, Thurber RV, Wegley L, White BA, Rohwer F: Functional metagenomic profiling of nine biomes. Nature 2008, 452:629-632.

48. Simon C, Wiezer A, Strittmatter AW, Daniel R: Phylogenetic diversity and metabolic potential revealed in a glacier ice metagenome. Appl Environ Microbiol 2009, 75:7519-7526. 
49. Friedrich CG: Physiology and genetics of sulfur-oxidizing bacteria. Adv Microb Physiol 1998, 39:235-289.

50. Meyer B, Imhoff JF, Kuever J: Molecular analysis of the distribution and phylogeny of the soxB gene among sulfur-oxidizing bacteria - evolution of the Sox sulfur oxidation enzyme system. Environ Microbiol 2007, 9:2957-2977.

51. Hipp WM, Pott AS, Thum-Schmitz N, Faath I, Dahl C, Trüper HG: Towards the phylogeny of APS reductases and sirohaem sulfite reductases in sulfate-reducing and sulfur-oxidizing prokaryotes. Microbiology 1997, 143:2891-2902.

52. Meyer B, Kuever J: Molecular analysis of the distribution and phylogeny of dissimilatory adenosine-5'-phosphosulfate reductase-encoding genes (aprBA) among sulfur-oxidizing prokaryotes. Microbiology 2007, 153:3478-3498.

53. Lin JT, Goldman BS, Stewart V: Structures of genes nasA and nasB, encoding assimilatory nitrate and nitrite reductases in Klebsiella pneumoniae M5al. J Bacteriol 1993, 8:2370-2378.

54. Wang H, Gunsalus RP: The nrfA and nirB nitrite reductase operons in Escherichia coli are expressed differently in response to nitrate than to nitrite. J Bacterio/ 2000, 182:5813-5822.

55. Tchobanoglous G, Burton FL, Stensel HD: Wastewater Engineering: Treatment and Reuse. New York: McGraw-Hill; 2003.

56. Hallin $\mathrm{S}$, Jones CM, Schloter M, Philippot L: Relationship between N-cycling communities and ecosystem functioning in a 50-year-old fertilization experiment. ISME J 2009, 3:597-605.

57. Wilson MJ, Bell N: Acid deposition and heavy metal mobilization. Appl Geochem 1996, 11:133-137.

58. Nies DH: Microbial heavy-metal resistance. Appl Microbiol Biotechnol 1999, 51:730-750.

59. Silver S, Phung LT: Bacterial heavy metal resistance: new surprises. Annu Rev Microbiol 1996, 50:753-789.

60. Arsène-Ploetze F, Koechler S, Marchal M, Coppée JY, Chandler M, Bonnefoy V, Brochier-Armanet C, Barakat M, Barbe V, Battaglia-Brunet F, Bruneel O, Bryan CG, Cleiss-Arnold J, Cruveiller S, Erhardt M, Heinrich-Salmeron A, Hommais F, Joulian C, Krin E, Lieutaud A, Lièvremont D, Michel C, Muller D, Ortet P, Proux C, Siguier P, Roche D, Rouy Z, Salvignol G, Slyemi D, Talla E, Weiss S, Weissenbach J, Médigue C, Bertin PN: Structure, function, and evolution of the Thiomonas spp. genome. PLoS Genet 2010, 6:e1000859.

61. Sauer K: The genomics and proteomics of biofilm formation. Genome Biol 2003, 4:219.

62. Chávez FP, Gordillo F, Jerez CA: Adaptive responses and cellular behaviour of biphenyl-degrading bacteria toward polychlorinated biphenyls. Biotechnol Adv 2006, 24:309-320.

63. Boor KJ: Bacterial stress responses: what doesn't kill them can make then stronger. PLOS Biol 2006, 4:e23.

64. Persson OP, Pinhassi J, Riemann L, Marklund BI, Rhen M, Normark S, González JM, Hagström A: High abundance of virulence gene homologues in marine bacteria. Environ Microbiol 2009, 11:1348-1357.

65. Rao V, Ghei R, Chambers Y: Biofilms research - implications to biosafety and public health. Appl Biosafety 2005, 10:83-90.

66. Grady CPL Jr: Daigger GT, NG Love, Filipe CDM: Biological Wastewater Treatment. New York: Marcel Dekker; 2011.

67. Daum M, Zimmer W, Papen H, Kloos K, Nawrath K, Bothe H: Physiological and molecular biological characterization of ammonia oxidation of the heterotrophic nitrifier Pseudomonas putida. Curr Microbiol 1998, 37:281-288.

68. Rotthauwe J-H, Witzel K-P, Liesack W: The ammonia monooxygenase structural gene $a m o A$ as a functional marker: molecular fine-scale analysis of natural ammonia-oxidizing populations. Appl Environ Microbiol 1997, 63:4704-4712

69. Petri R, Podgorsek L, Imhoff JF: Phylogeny and distribution of the soxB gene among thiosulfate-oxidizing bacteria. FEMS Microbiol Lett 2001, 197:171-178.

70. Little B, Lee J, Ray R: A review of 'green' strategies to prevent or mitigate microbiologically influenced corrosion. Biofouling 2007, 23:87-97.

71. Videla HA, Herrera LK: Microbiologically influenced corrosion: looking to the future. Int Microbiol 2005, 8:169-180.

72. Yan T, Fields MW, Wu L, Zu Y, Tiedje JM, Zhou J: Molecular diversity and characterization of nitrite reductase gene fragments (nirK and nirS) from nitrate- and uranium-contaminated groundwater. Environ Microbiol 2003, 5:13-24. doi:10.1186/1471-2180-12-122

Cite this article as: Gomez-Alvarez et al: Metagenome analyses of corroded concrete wastewater pipe biofilms reveal a complex microbial system. BMC Microbiology 2012 12:122.

\section{Submit your next manuscript to BioMed Central and take full advantage of:}

- Convenient online submission

- Thorough peer review

- No space constraints or color figure charges

- Immediate publication on acceptance

- Inclusion in PubMed, CAS, Scopus and Google Scholar

- Research which is freely available for redistribution 